\title{
Immunization with Irradiated Tumour Cells and Specific Lymphocyte Cytotoxicity in Malignant Melanoma
}

\author{
G. A. CURRIE， F. LEJEUNE， G. HAMILTON FAIRLEY
}

British Mcdical fournal, 1971, 2, 305-310

\section{Summary}

A microculture technique has been adapted to assay the cytotoxic properties of the lymphocytes from patients with malignant melanoma when cultured with their autologous tumour cells. In a series of patients with established melanoma specific autologous cytotoxicity was extremely uncommon, being detectable in only 3 out of the 22 cases studied. This cytotoxicity did not correlate with clinical staging of the disease but may well have been related to tumour volume. By autoimmunization of patients with an irradiated suspension of their own tumour cells the appearance of cytotoxic lymphocytes could be provoked in 5 out of the 12 patients studied. This cytotoxicity was detectable at the end of the first week after the autograf: and disappeared by the third week. Cytotoxic lymphocytes did not correlate in any obvious way with the appearance of specific antitumour antibodies detected by immunofluorescence. So far there has been no evidence of a serum factor capable of blocking the lymphocyte cytotoxicity in these patients.

The presence and possible significance of cytotoxic lymphocytes in patients with malignant disease is discussed.

\section{Introduction}

The existence of tumour-associated antigens and of host reactions to them is well documented in several species of laboratory animal (Old and Boyse, 1964) and there is now increasing evidence for the existence of such antigens in at least some human tumours, notably Burkitt's lymphoma (Klein et al., 1967), acute leukaemia (Fridman and Kourilsky, 1969), and malignant melanoma (Morton et al., 1968). A study of specific immune reactions to the antigens of their own tumours may help to show the extent and influence of these reactions in moderating tumour growth and development in patients with established malignant disease. Furthermore, it may help to suggest possible means of mobilizing such host defence mechanisms as part of the strategy of treatment.

In the serum of patients with malignant melanoma specific antitumour antibodies have been detected in the early stages of the disease (Lewis et al., 1969). These antibodies disappear from the peripheral blood as the disease progresses and are undetectable in the serum of cases with widespread metastatic melanoma. Nevertheless, an autologous graft of irradiated tumour cells in such patients may provoke the transient reappearance of antibodies (Ikonopisov et al., 1970). Tumour immunity in experimental animals resembles transplantation immunity and is manifested by predominantly cell-mediated reactions of

Chester Beatty Research Institute, Belmont, Sutton, Surrey G. A. CURRIE, M.B., M.R.C.P., Member of Scientific Staff Chester Beatty Research Institute, Fulham Road, London S.W.3 F. LEJEUNE, M.D., Research Fellow

G. HAMILTON FAIRLEY, D.M., F.R.c.P., Consultant Physician and at St. Bartholomew's Hospital, London E.C.1. the delayed hypersensitivity type. While the precise nature of the cellular events involved in the efferent phase of a cellmediated response is still far from clear, the existence of specifically cytotoxic lymphocytes has been demonstrated by in-vitro tests in an animal tumour system (Takasugi and Klein, 1970).

This communication describes experiments designed to detect and quantitate the specific cytotoxic properties of peripheral blood lymphocytes when confronted in short-term cultures with autologous tumour cells in a series of patients with malignant melanoma. The effect of irradiated tumour cell autografts on the cytotoxicity of patients' lymphocytes is also described.

Studies of specific antitumour cell-mediated immunity in patients with advanced cancer have been described by Hellström et al., (1968). We have used a different technique for detecting lymphocyte cytotoxicity and, mindful of the difficulties involved in short-term tissue culture of human tumours, we have used an electron microscopic method for identifying the nature of the target cells studied. Our results differ radically from those reported by Hellström and her group and possible reasons for the differences are discussed at the end of this paper.

\section{Patients and Methods}

The patients investigated in this study were seen mainly at surgical and radiotherapy clinics at a specialized cancer hospital and were consequently a selected series, as most of them had some degree of metastatic spread either to regional lymph nodes, the skin, or viscera.

\section{TUMOUR CELL SUSPENSIONS}

Fragments of melanoma were obtained at operation and placed in sterile medium 199, transported direct to the laboratory, and used immediately. The tumour fragments were trimmed, washed in tissue culture medium 199, finely minced with a pair of scalpel blades, and the subsequent suspension was filtered through a double layer of lint-free cotton gauze. The resultant cell suspension was washed and the cell concentration counted with a haemacytometer. This tumour cell suspension was either irradiated and used immediately or frozen in $10 \%$ dimethyl sulphoxide in a liquid nitrogen refrigerator.

\section{LYMPHOCYTES}

Lymphocytes were isolated from sterile defibrinated venous blood with carbonyl iron and sedimentation with methyl cellulose.

\section{QUANTITATION OF LYMPHOCYTE TOXICITY}

The technique used was adapted from the microassay described by Takasugi and Klein (1970). The tumour cells used as targets for the cytotoxicity of lymphocytes were always from mechanically prepared cell suspensions and did not undergo 
any subculturing; they were cultured either on the day of operation or after a brief period of storage in liquid nitrogen.

The tumour cell suspensions were made up in TC199 containing $20 \%$ heat-inactivated fetal calf serum and placed into the wells of plastic microtest culture plates (Falcon Plastics No. 3034), a microsyringe with a repeating dispenser attachment being used. Ten microlitres of cell suspension was inoculated into each well. The cell concentration of this original inoculum was varied, depending on the dye exclusion viability of the cell suspension (from 10 to $30 \%$ ). The usual cell concentration was $0.5 \times 10^{6} / \mathrm{ml}$. The plates were then placed in an airtight moist chamber, gassed with $5 \% \mathrm{CO}_{2}$ in air, and incubated at $37^{\circ}$ for 20 hours. At this time the plates were inverted and reincubated for a further two hours to allow unattached dead cells and debris to detach from the bottom of the wells.

Serial dilutions of the patients' lymphosytes were made in TC199 containing $20 \%$ human AB serum or $20 \%$ autologous patients' serum. The inverted microplate cultures were examined under phase contrast and the mean number of attached cells was counted. The serial dilutions were adjusted to give lymphocyte: tumour-cell ratios in a $10-\mu \mathrm{l}$ well from approximately $500: 1$ downwards in doubling dilutions. The supernatant fluids from the cell cultures were gently aspirated from each well with a fine disposable needle and replaced with $10 \mu \mathrm{l}$. of either the lymphocyte suspensions or the appropriate diluent media. Thus each microplate culture received a series of lymphocyte dilutions (usually in triplicate) and the corresponding serum-medium diluents. Usually three replicate plates were put up for each patient studied and incubated for 24,48 , or 72 hours. At the end of the incubation period the plates were inverted for two hours, and examined under phase contrast. For permanent preparation they were gently washed with TC199, fixed with methanol, and stained with Giemsa. The fixed, stained plates were examined under light microscopy with a $\times 10$ objective and the number of cells in each well was counted with an eyepiece graticule.

The mean number of cells in the control wells was calculated and from the mean number of cells remaining in the lymphocyte-treated wells it was possible to construct a cytotoxicity curve of the percentage of tumour cells killed by different ratios of lymphocytes to melanoma cells.

$$
\% \text { Cytotoxicity }=\frac{- \text { Mean No. cells in control well }}{\text { Mean No. in lymphocyte well }} \mid 100
$$

The assumption was made that detachment of cells from the plastic is a good index of lymphocyte-induced cell death. A pilot study had shown an excellent correlation between microplate assay results and the release of chromium-51 when cells were killed by lymphocytes. The lymphocytes from the patients were incubated with autologous tumour cells, with allogeneic melanoma cells, and with other types of tumour. Lymphocytes from normal healthy volunteers were also tested on some melanoma cultures.

\section{TUMOUR CELL AUTOGRAFTS}

Where feasible the patients were immunized with their own irradiated tumour cells. Between 300 and $500 \times 10^{6}$ autologous melanoma cells were irradiated with 12.5 krads in a cobalt- 60 source and then injected into the patients in five distinct subcutaneous sites in an attempt to stimulate as many major lymph node chains as possible. Serum and lymphocytes were obtained from the patients before and at intervals after the autograft.

In the overall design of this study clearly there is no adequate control for the specificity of lymphocyte cytotoxicity apart from its cross-reaction on other tumours. There is no "control lym- phocyte" as the use of normal allogeneic lymphocytes is obviously unsatisfactory owing to the possible intervention of histocompatibility antigens in the cytotoxicity test. Nevertheless, a few experiments were performed with such lymphocytes, but the only appropriate control situation will be found if tumour autografting produces a change in lymphocyte toxicity -that is, the patients' lymphocytes before autografting will act as the control for those obtained afterwards. Furthermore, the other control for specificity would be to test the patients' lymphocytes on cultures of autologous normal cells such as fibroblasts. This had not been practicable as the immediate use of mechanically prepared cell suspensions without subcultures precludes the development of such appropriate control cell cultures in time.

One major problem besetting a study such as this is that the target cells used may not in fact be tumour cells-that is, macrophages or fibroblasts may be selectively isolated by the cell suspension and culture technique. By studying malignant melanoma this problem is more readily overcome. Frankly melanotic tumours usually gave adequate cultures of wellpigmented cells but some melanotic tumours had provided more difficulty. To confirm the identity of the target cells being studied the microplate cultures were examined by electron microscopy.

\section{ELECTRON MICROSCOPY}

The microplate cultures were carefully rinsed in medium 199 and then fixed with $1 \%$ freshly distilled glutaraldehyde in $0.08 \mathrm{M}$ cacodylate buffer at $\mathrm{pH} 7.2$ for 30 minutes at room temperature. After fixation in $1 \%$ osmium tetroxide in veronal acetate buffer and dehydration, the cells were embedded in situ in Epon by filling each well individually. After polymyerization at $60^{\circ} \mathrm{C}$ overnight, prepolymerized blocks of Epon were mounted on to the base of selected cones occupying the wells with Araldite glue. Finally, the prepared block was pulled out of the Terasaki plate and cut parallel to the surface of the monolayer.

\section{Results}

The quality of the melanoma cell cultures obtained in the microplate wells was extremely variable and seemed to be related to the initial viability of the cell suspension used (Fig. 1). When any cytotoxic effects of the lymphocytes were detected there was no difference between 48-hour and 72-hour cultures, and the results mentioned here were all obtained at 48 hours.

The first series of experiments was concerned with testing the effects of normal allogeneic lymphocytes to provide some form of baseline curves for the effect of non-cytotoxic lymphocytes.

EFFECT OF NORMAL ALLOGENEIC LYMPHOCYTES ON MELANOMA CELLS

Lymphocytes from 12 normal subjects were tested against a panel of melanoma cell cultures. Eleven of these produced no evidence of damage in the target cells at all ratios tested. However, at $300: 1$ there was occasionally a reduction in survival of the melanoma cells at 48 hours. At such high cell concentrations this finding is perhaps not unexpected and can be attributed to exhaustion of the medium. In no case was there greater than $50 \%$ cytotoxicity at ratios up to $300: 1$. This value was therefore chosen as an arbitrary end-point for the cytotoxicity test. The lymphocytes from the twelfth normal individual were extremely toxic to melanoma cells even at extremely low ratios. A typical cytotoxicity curve produced by his lymphocytes is shown in Fig. 2 and compared with a cumulative curve of the other 11 normals. 

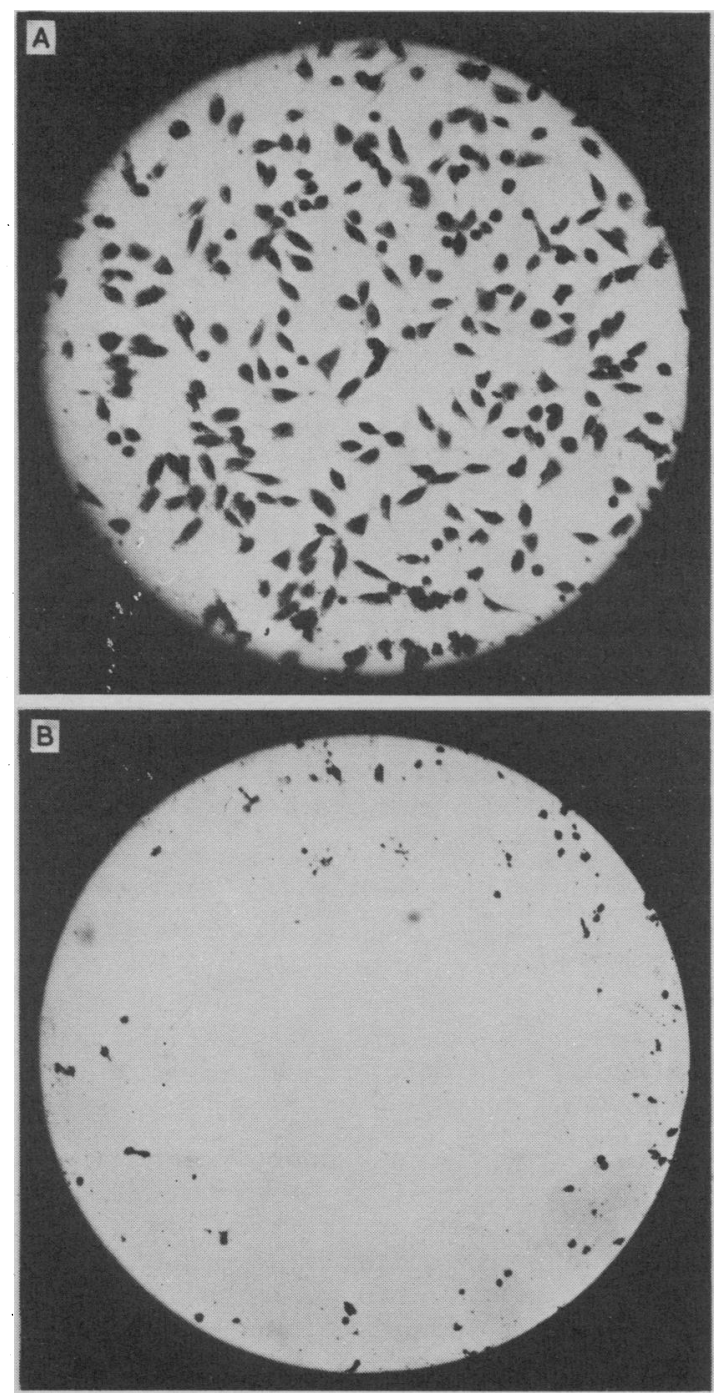

FIG. 1-Microphotograph of entire microplate cell cultures of melanoma cells (Case 177). A, incubated without lymphocytes. $B$, incubated for 48 hours with autologous lymphocytes obtained six days after autoimmunization with irradiated tumour cells. Original magnification : $x 60$.

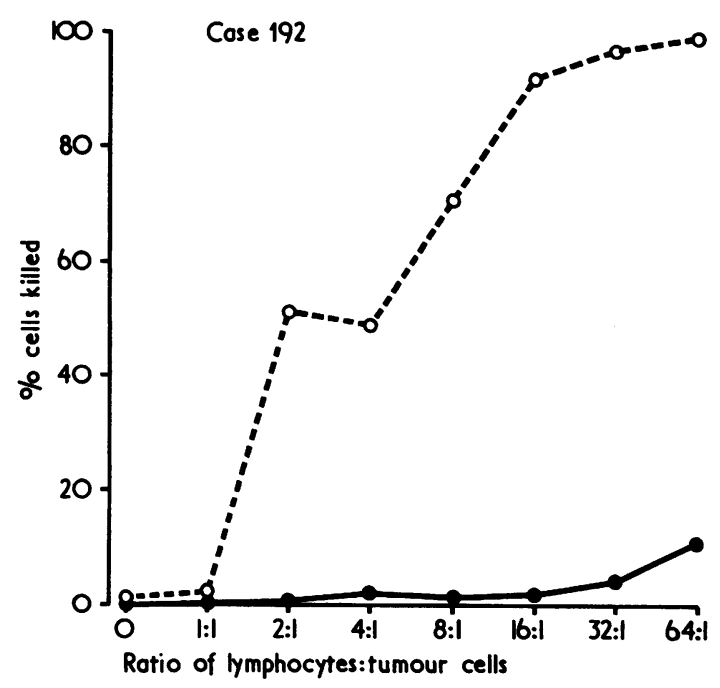

FIG. 2-Effect of normal allogeneic lymphocytes on melanoma cells (from Case 192). The continuous line is a cumulative curve of results from 11 normal individuals whose lymphocytes were non-toxic. The dotted line shows the powerful cytotoxic effect of lymphocytes from one normal
individual.
EFFECT OF AUTOLOGOUS LYMPHOCYTES ON MELANOMA CELLS

Satisfactory cultures, suitable for testing, were obtained from 22 cases of malignant melanoma (Table I). Of these, only three patients possessed lymphocytes which could be described as cytotoxic - that is, $50 \%$ cytotoxicity at ratios of less than $300: 1$. The remaining 19 cases were all negative-that is, there was no evidence of target cell destruction at ratios of lymphocytes to tumour cells up to $300: 1$ (see Fig. 3). The three "positive" cases had established malignant melanoma when judged by conventional clinical staging. The first (case 218) was clinically in stage II with a recurrent primary lesion of the hand and no evidence of spread to regional lymphatics or beyond. The second (Case 239) was in stage III with a solitary small subcutaneous distant metastasis following excision of the primary lesion, as was the third (case 258). It is of interest that these three cases had, in clinical terms, the smallest observable tumour volumes of the series of 22 cases examined.

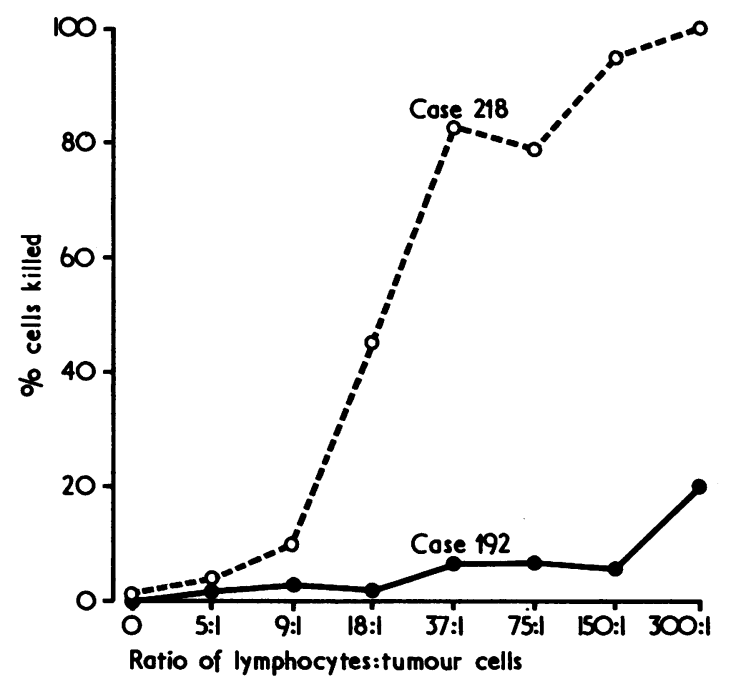

FIG. 3-Autologous lymphocyte cytotoxicity curves from two cases, one (Case 218) having powerfully toxic lymphocytes and the other (Case 192) showing no evidence of cytotoxicity.

TABLE I-Presence of Cytotoxic Lymphocytes and Specific Antimelanoma Antibodies in 22 Cases of Malignant Melanoma

\begin{tabular}{|c|c|c|c|c|c|c|}
\hline \multicolumn{5}{|c|}{ Case No. } & $\begin{array}{l}\text { Lymphocyte } \\
\text { Cytotoxicity }\end{array}$ & $\begin{array}{l}\text { Antibndies Detected } \\
\text { by Membrane }\end{array}$ \\
\hline $\begin{array}{l}218 \\
239 \\
258 \\
177^{*} \\
181^{*} \\
182^{*} \\
189^{*} \\
190 \\
192^{*} \\
193^{*} \\
195 \\
198 \\
203^{*} \\
224^{*} \\
230^{*} \\
233^{*} \\
245 \\
246^{*} \\
247 \\
249 \\
253 \\
255^{*}\end{array}$ & $\begin{array}{l}\because \\
\because \\
\because \\
\because \\
\because \\
\because \\
\because \\
\because \\
\because \\
\because \\
\because \\
\because\end{array}$ & $\begin{array}{l}\because \\
\because \\
\because \\
\because \\
\because \\
\because \\
\because \\
\because \\
\because \\
\because \\
\because \\
\because \\
\end{array}$ & $\begin{array}{l}\because \\
\because \\
\because \\
\because \\
\because \\
\because \\
\because \\
\because \\
\because \\
\because \\
\because \\
\because \\
\because\end{array}$ & $\begin{array}{l}\because \\
\because \\
\because \\
\because \\
\because \\
\because \\
\because \\
\because \\
\because \\
\because \\
\because \\
\because \\
\end{array}$ & $\begin{array}{c}\text { Positive } \\
\text { "” } \\
\text { Negative } \\
\text { " } \\
" \\
" \\
" \\
" \\
" \\
" \\
" \\
" \\
" \\
" \\
"\end{array}$ & 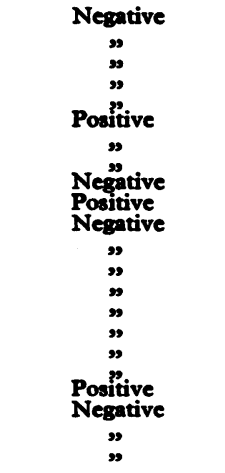 \\
\hline
\end{tabular}

* Cases subsequently given an irradiated tumour cell autograft.

\section{EFFECT OF TUMOUR AUTOGRAFTING ON LYMPHOCYTE CYTOTOXICITY}

Twelve of the 19 patients with non-cytotoxic lymphocytes were given an autograft of irradiated melanoma cells in five subcutaneous sites and their lymphocytes were tested for cytotoxicity one week later. In five the post autograft lymphocytes were strongly cytotoxic when compared with their own pretreatment results (see Fig. 4 and Table II). 


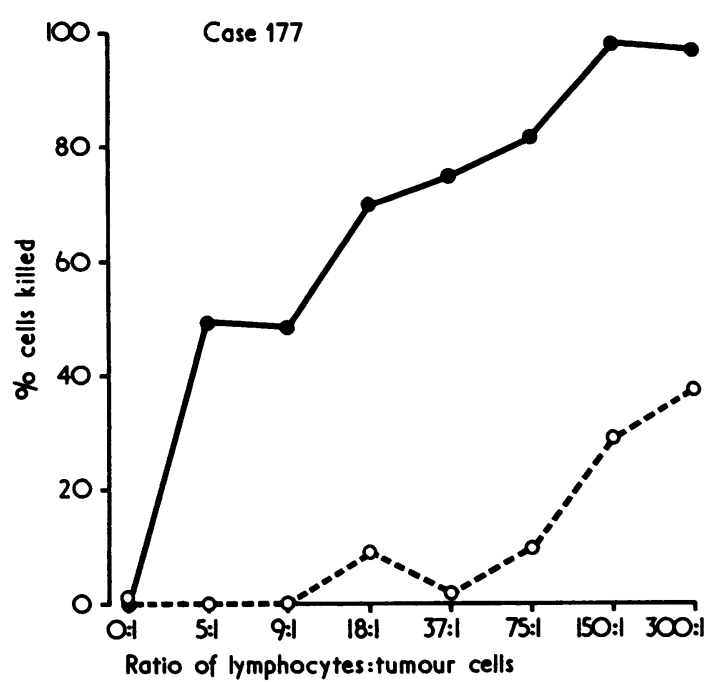

FIG. 4-Case 177. Cytotoxicity curves of the effect of autologous lymphocytes before ( $0---O)$ and six days after ( with irradiated tumour cells showing a dramatic increase in cytotoxicity.

TABLE II-Effect of Autoimmunization with Irradiated Tumour Cells on Lymphocyte Cytotoxicity and the Presence of Antibodies detected by Membrane Immunofiuorescence

\begin{tabular}{|c|c|c|c|c|}
\hline \multirow{2}{*}{ Case No. } & \multicolumn{2}{|c|}{ Lymphocyte Cytotoxicity } & \multicolumn{2}{|c|}{ Membrane Immunofluorescence } \\
\hline & Pre-autografted & Day 6 & Pre-autografted & Day 6 \\
\hline $\begin{array}{l}230 \\
255 \\
177 \\
181 \\
182 \\
189 \\
192 \\
193 \\
203 \\
224 \\
233 \\
246\end{array}$ & $\begin{array}{c}\text { Negative } \\
\text { "' } \\
" \\
" \\
" \\
" \\
" \\
"\end{array}$ & $\begin{array}{c}\text { Positive } \\
\text { " } \\
\text { " } \\
\text { Neggative } \\
\text { "' } \\
\text { " } \\
\text { "' }\end{array}$ & $\begin{array}{c}\text { Negative } \\
\text { ", } \\
\text { "’ } \\
\text { Positive } \\
\text { Negative } \\
\text { Positive } \\
\text { Negative } \\
\text { ", } \\
\text { ", }\end{array}$ & $\begin{array}{c}\text { Negative } \\
\text { Positive } \\
\text { Negative } \\
\text { Positive } \\
\text { Neggative } \\
\text { Positive } \\
\text { Negative } \\
\text { "” } \\
\text { "” }\end{array}$ \\
\hline
\end{tabular}

The opportunity to study the persistence of cytotoxic lymphocytes occurred only in one (Case 255). In this patient the lymphocytes became cytotoxic at seven days, remained so at 14 days, but were without cytotoxic effect when tested 21 days after the autograft.

EFFECT OF POSTAUTOGRAFT CYTOTOXIC LYMPHOCYTES ON ALLOGENEIC MELANOMA CELLS

If the cytotoxicity test reflects cell-mediated immune responses are the lymphocytes reacting to cross-reacting tumour antigens or are the antigens, presumably on the cell surface, individual tumour specific? The lymphocytes from Case 255, powerfully cytotoxic at 14 days after the autograft, were tested on six other melanoma cultures, on fibrosarcoma cells, and on HeLa cells. There was no evidence of cross-reacting cytotoxicity; only the cells from the autologous tumour were killed.

\section{WHAT IS THE EFFECT OF AUTOLOGOUS SERUM ON THE} CYTOTOXICITY OF LYMPHOCYTES?

The lymphocyte suspensions used were in a medium containing either human $\mathbf{A B}$ serum or autologous serum and thus it was possible to assess any inhibitory effect of serum factors on cytotoxicity. There was no evidence in any case of a significant difference between the cytotoxic effect of lymphocytes suspended in $A B$ serum or those in autologous serum (see Fig 5).
Further studies of the effects of pre-incubation of the target cells with higher concentrations of autologous serum are still in progress.

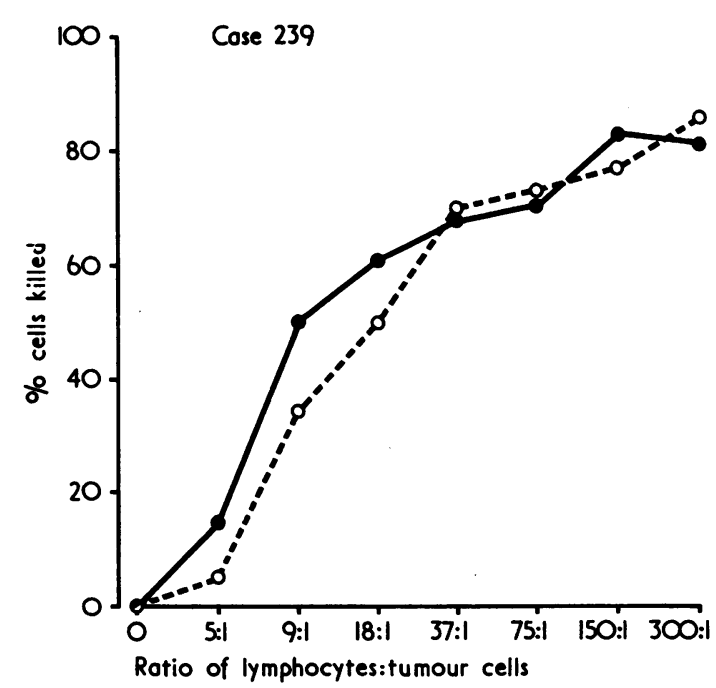

FIG. 5-Case 239. Effect of autologous serum on lymphocyte cytotoxicity showing no evidence of any blocking effect. Autologous lymphocytes + normal human serum. $\mathrm{O}-\mathrm{-}_{--} \mathrm{O}$ Autologous lymphocytes + autologous serum.

DOES LYMPHOCYTE CYTOTOXICITY CORRELATE WITH ANTITUMOUR ANTIBODY STATUS?

The results of membrane immunofluorescence tests for antitumour antibodies are shown in Tables I and II and do not appear to show any clear-cut correlation with the results of lymphocyte cytotoxicity testing either before or after autografting - that is, patients with no detectable antibodies had cytotoxic lymphocytes, and in one (Case 189) there were detectable antibodies but the lymphocytes were not cytotoxic.

\section{ELECTRON MICROSCOPY OF TARGET CELLS}

Ultrastructural studies of the target cells in situ showed that there was variation in the type of cell successfully cultured but confirmed that most cells examined in this study were typical melanoma cells. Such were present in about $70 \%$ of cultures showing a definite synthesis of melanin by the presence of premelanosomes and melanosomes isolated in the cytoplasm (Fig. 6). Moreover, some cells were exhibiting dendritic processes bearing melanin. In addition, these cells had a very indented nucleus with large irregular nucleolus, an enlarged smooth reticulum, and many clear vacuoles.

It is well established that melanocytes differ from pigmented macrophages (known as melanophages) by the fact that they are the only cell types able to synthesize melanin granules-namely, with immature premelanosomes and mature melanosomes (Birbeck et al., 1956; Barnicot and Birbeck, 1959; Drochmans, 1963; Seiji et al., 1963). Macrophages contain only phagocytosed melanin in lysosomes, though malignant melanocytes may also contain some such lysosomes (Drochmans, 1963; Mishima, 1966). It is worth pointing out that some melanoma cells stored in liquid nitrogen retained their capacity for the synthesis of melanin (Fig. 6) when cultured.

In some other cultures there were two main types of cell which could have led to confusion when examined by light microscopy. Firstly, there were frankly malignant cells with abnormal nuclei but the typical melanosome system was absent and replaced by scattered small bodies containing myeliniclike formations, surrounded by a double membrane (Fig. 7). Such organelles have already been reported in in-vitro condi- 

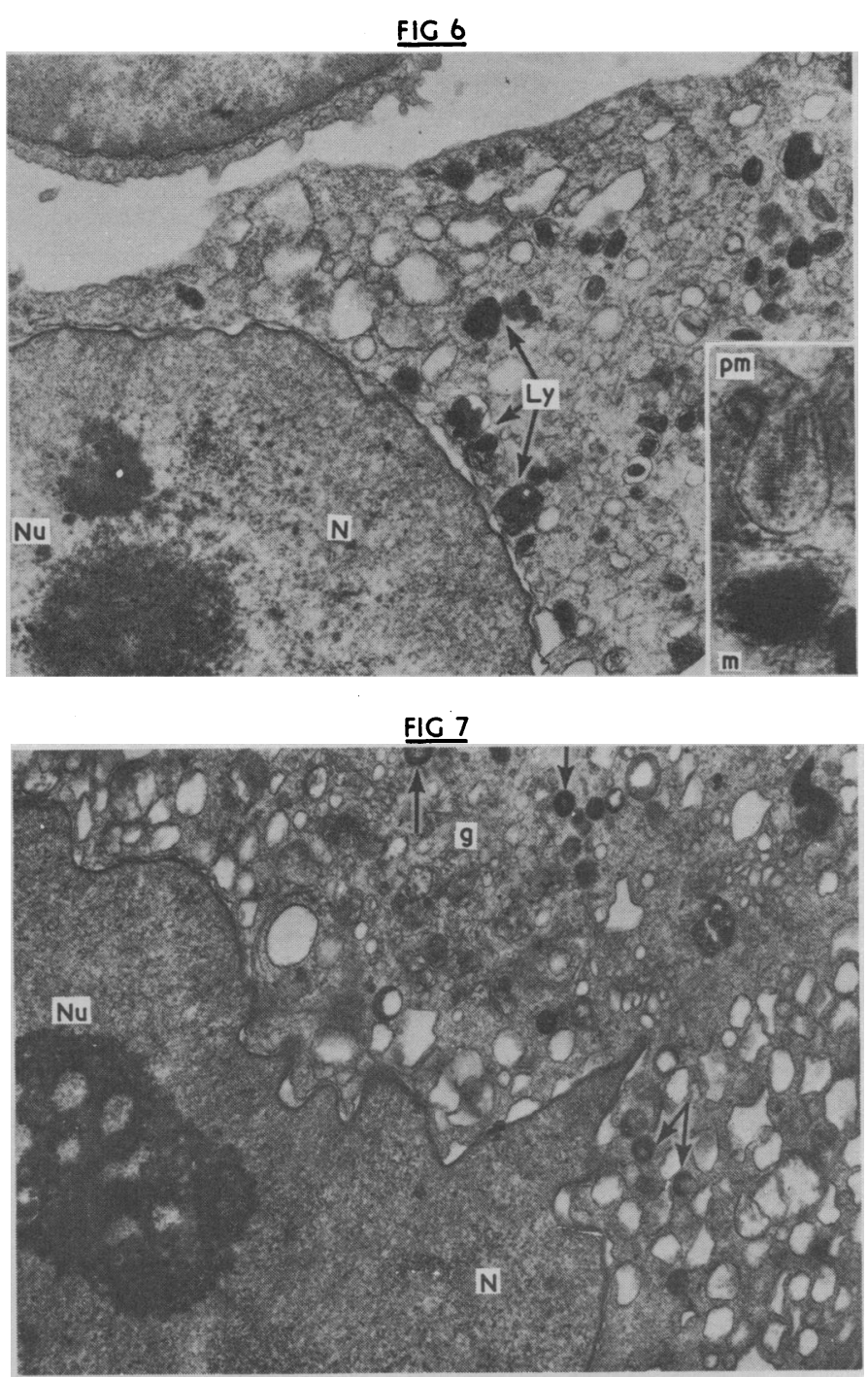

FIG. 6-Malignant melanocyte cultured for two days after storage in liquid nitrogen. Most of the dark granules in the cytoplasm are single melanonitrogen. Most of the dark granules in the cytoplasm are single melanosomes, while some are inside lysosomal membranes ( $L y)$. The inset shows one pretmelanosome with its characteristic striations (pm) and one melanosome $(\mathrm{m}) . \mathrm{N}=$ Nucleus. $\mathrm{Nu}=$ Nucleolus. Original magnifications: $\times 16,000$
and $\times 8,000$ (inset).

FIG. 7-Atypical malignant melanocyte with an indented nucleus (N) and enormous nucleolus (Nu). Around the Golgi region (g) are scattered small bodies with concentric lamellations (arrows). Original magnification: $\times 16,000$.

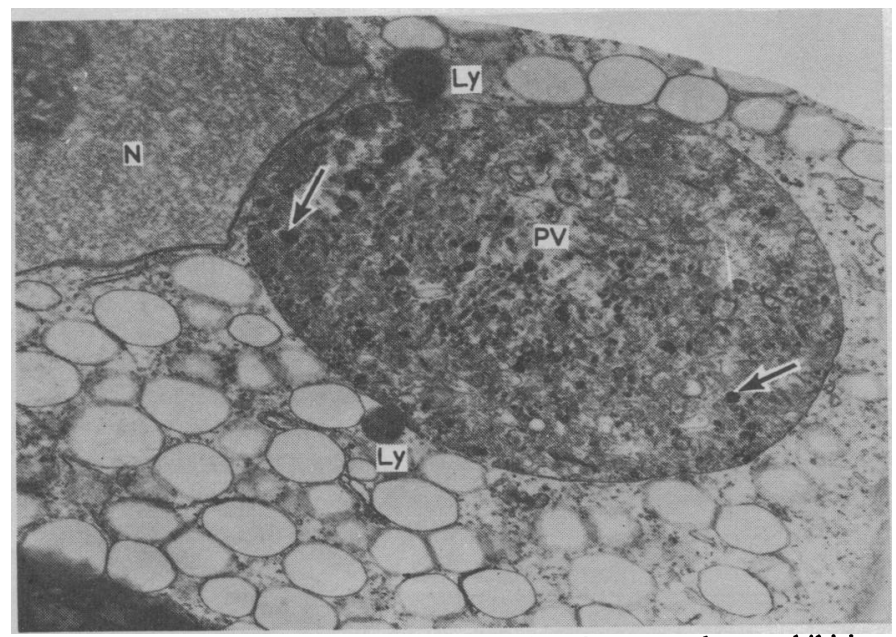

FIG. 8-Macrophage present in a pigmented melanoma culture exhibiting, close to the nucleus $(\mathrm{N})$, a huge phagocytic vacuole (PV) filled with a variety of melanin debris and a few melanosomes (arrows). Two lysosome
$(\mathrm{Ly})$ are in contact with the vacuole. Original magnification: $\times 13,500$. tions by $\mathrm{Hu}$ (1967) as typical for an unpigmented subline of mouse melanoma and which she considered as abnormal melanosomes. Though this point was not well demonstrated we tended to regard these cells as melanoma cells. Moreover, we also found such organelles in cultured pigmented melanoma cells.

The second abnormal cell was consistently larger with a regular nucleus, very numerous small vacuoles, and some larger phagocytic vacuoles (Fig. 8) containing melamin at various stages of degradation. These cells showed no sign at all of melanin synthesis and were considered as macrophages or epithelioid macrophages. Occasional cultures were indeed shown to consist almost entirely of such macrophages despite their resemblance to melanoma cells by light microscopy.

\section{Discussion}

Specific cytotoxic lymphocytes, capable of destroying autologous tumour cells in vitro and detected in a microassay technique, were uncommon in the present series of patients with malignant melanoma. Only in 3 out of the 22 cases tested were such cells found in the peripheral blood. After autoimmunization with irradiated tumour cells, however, peripheral blood lymphocytes became cytotoxic in 5 out of the 12 cases so treated. This cytotoxic reaction appeared to be specific to the individual tumour. Clear-cut cross-reactions in lymphocyte cell-killing were not seen either on allogeneic melanoma cells or on other types of tumour cell. There has been no evidence so far of a blocking factor in the serum capable of specifically inhibiting lymphocyte cytolysis of melanoma cells.

The presence of cytotoxic lymphocytes did not appear to correlate with simple clinical staging of the disease. Nevertheless, there may have been a relation between the status of the lymphocytes and total tumour volume. The three patients with spontaneously cytotoxic lymphocytes had clinical evidence of only minute volumes of tumour, though in two of the cases the tumour was present as distant metastases. In an earlier study of antimelanoma antibodies (Lewis et al., 1969) there was a close correlation between simple clinical staging of the disease and the presence of antibodies. In the present series of cases the presence of such antibodies did not correlate in any obvious way with the cytotoxic status of the lymphocytes in either the spontaneous or the autografted cases.

Hellström et al. (1968) found evidence of specific cellular immunity in all the patients studied in a series containing a variety of advanced malignant tumours including melanoma. Their method assayed the inhibitory effect of lymphocytes on the formation of colonies in vitro by tumour cells. The target cells were obtained by using trypsin, and the colony-forming cells were then exposed to massive concentrations of lymphocytes-that is, up to $5 \times 10^{6}$ lymphocytes were added to between 50 and 100 colony-forming cells. Using this method, they also showed that the colony inhibiting properties of the lymphoid cells were not individual tumour specific. They were able to show complete cross-reactions between tumours of similar histological type (Hellström et al., 1971).

The discrepancy in results between their series and ours is probably related to the techniques used. Each technique has an entirely different end-point. The cytotoxic destruction of the tumour cells as detected in our system may well involve a set of tumour antigens different from those involved in colony inhibition, and this may account for both the relative rarity of cytotoxic lymphocytes and the lack of cross-reactions between tumours detected in our series. Lewis et al. (1969) demonstrated two different antigen systems in malignant melanoma cells. The first was an individual tumour-specific antigen on the cell membrane and the second a cross-reacting system of cytoplasmic antigens. Probably the microassay of cell-mediated immunity used in the present series is detecting the individual specific membrane antigens. 
The physiological significance of these cytotoxic lymphocytes is unknown. The detection of such an in-vitro index of cell-mediated immunity may not reflect events in vivo. Though cytotoxic small lymphocytes are involved in the efferent pathway of cellular immune reactions little is known about the precise nature and properties of the effector cell type, especially in immune responses involving tumours. Macrophages, immunoblasts, and the cytotoxic small lymphocyte may all be involved in the final destructive phase of a cell-mediated host response.

By analogy with animal models of the immune response to established tumours it is perhaps surprising that cytotoxic lymphocytes should be detected at all in the peripheral blood. The lymph nodes draining a tumour are under constant bombardment by tumour antigen, do not release specific immunoblasts (Alexander et al., 1967), and thus the propagation of the immune response is inhibited. Only after excision of the tumour or autografting at distant sites are specifically activated immunoblasts disseminated into the circulation and a systemic immune response allowed to develop.

Such an animal system may provide a model for the autografting of the patients-that is, cytotoxic lymphocytes appearing in response to autografting would suggest that regional node paralysis may play an important part in inhibiting host defence mechanisms and that it can be bypassed in some patients by involving previously unaffected regional lymph nodes with injected tumour antigen. The fact that only half the autografted cases developed cytotoxic lymphocytes may well imply that some of the regional node chains may already have been involved by clinically undetected tumour. In view of the difficulty in assessing the extent of tumour dissemination in patients with established malignant melanoma, it was not possible to observe any clinical difference between patients whose lymphocytes responded to autografting and those whose lymphocytes were unaffected.

From the literature concerning the treatment of advanced cancer patients with autologous tumour cells there is no evidence that any clinical benefit is likely to ensue from such a procedure (Graham and Graham, 1959; Southam, 1961; Cunningham et al., 1969). The present series of cases, along with those presented by Ikonopisov et al. (1970), confirm such a conclusion. There was no indication of any clinical improvement induced by autografting with irradiated melanoma cells.

Thus the development of in-vitro cytotoxic lymphocytes in the five patients who responded to their autograft was not associated with any clinically detectable in-vivo killing of tumour cells. As a vigorous immune response is capable of killing only very few syngeneic tumour cells in vivo, the potential value of active immunotherapy in controlling tumours is likely to be valuable merely as an adjunct to more vigorously successful cytoreductive forms of treatment. Specific active immunotherapy with a tumour cell autograft is capable of inducing a detectable cell-mediated response in some patients and may become part of a combined therapeutic approach to cancer treatment.

This work has been supported by grants made to the Chester Beatty Research Institute by the Cancer Research Campaign and the Medical Research Council.

We wish to thank our surgical colleagues, especially $\mathrm{Mr}$. C. I. Cooling, for their enthusiastic co-operation. The skilled technical assistance of Miss D. Malinowska, Mrs. G. Bhatia, and Mr. M. Lovell is gratefully acknowledged. Special thanks are due to Professor Peter Alexander for his constant encouragement and advice and to Mr. M. Birbeck for helpful discussions.

\section{References}

Alexander, P., Bensted, J., Delorme, E. J., Hall, J. G., and Hodgett, J. (1967). Proceedings of the Royal Society, B 174, 237.

Barnicot, N. A., and Birbeck, M. S. C. (1959) In Pigment Cell Biology, ed. M. Gordon, p. 549. New York, Academ c Press.

Birbeck, M. S. C., Mercer, E. H., and Barnicot, N. A. (1956). Experimental Cell Research, 10, 505.

Cunningham, T. J., Olson, K. B., Laffin, R., Horton, J., and Sullivan, I. (1969). Cancer (Philadedphia), 24, 392 .

Drochmans, P. (1963). International Reviews of Experimental Pathology, 2, 357.

Fridman, W. H., and Kourilsky, F. M. (1969). Nature, 224, 277.

Graham, J. B., and Graham, R. M. (1959). Surgery, Gynecology and Obstetrics, 109, 131.

Hellström, I., Hellström, K. E., Pierce, C. E., and Yang, J. P. S. (1968), Nature, 220, 1352.

Hellström, I., Hellström, K. E., Sjögren, H. O., and Warner, G. A. (1971). International fournal of Cancer, 7 , 1 .

$\mathrm{Hu}, \mathrm{F}$. (1967). In Advances in Biology of Skin, cd. W. Montagna and F. $\mathrm{Hu}$, vol. 8. p. 549. Oxford, Pergamon.

Ikonopisov, R. L., et al., (1970). British Medical forrnal, 2. 752.

Klein, G., Klein, E., and Clifford, P. (1967). Cancer Research, 27, 2510.

Lewis, M. G., et al. (1969). British Medical fournal, 3, 547.

Mishima, Y. (1966). Fournal of Investigative Dermatology, 46, 70.

Morton, D. L., Malmgren, R. A., Holmes, E. C., and Ketcham, A. S. (1968). Surgery, 68, 233.

Old, L. J., and Boyse, E. A. (1964). Annual Reviews of Medicine, 15, 167. , M., Fitzpatrick, T.

outham, C. M.(1961). Cancer Research, 21, 1302.

Takasugi, M., and Klein, E. (1970). Transplantation, 9, 219.

\title{
Recommended Method for the Determination of Plasma Corticosteroids
}

\author{
REPORT BY A MEDICAL RESEARCH COUNCIL WORKING PARTY
}

The determination of plasma cortisol offers a useful means of investigating adrenocortical function, and several valuable diagnostic procedures have evolved on this basis and are becoming increasingly widely used. These procedures often offer considerable advantages over methods requiring urinary steroid analysis, and thus a growing number of clinical

Medical Research Council, London W1N 4AL

Report Prepared for the Clinical Endocrinology Committee by:

V. H. T. JAMES, D.SC., M.R.C.PATH., Professor of Chemical Endocrinology, St. Mary's Hospital, London W.2

D. MATTINGLY, M.B., F.R.C.P., Director, Postgraduate Medical Institute, Exeter

J. R. DALY, M.B., M.R.C.PATH., Senior Lecturer in Chemical Pathology, Charing Cross Hospital Medical School, London WC2N 4DZ laboratories are now performing plasma stcroid assays.

Initially, the only method which offered sufficient simplicity to merit consideration as a clinical chemical procedure was the colorimetric technique described by Silber and Porter (1954) and modified by others (Peterson, Karrer, and Guerra, 1957). The method, which depends on the colour reaction of cortisol and phenylhydrazine, was, nevertheless, in many people's hands difficult to operate, requiring considerable technical effort and skill, was relatively insensitive, and could hardly be considered sufficiently robust to merit consideration as an analytical technique suitable for a general diagnostic laboratory.

More recently, methods for the assay of "cortisol" in plasma have developed, based on the fluorescence which develops when cortisol or corticosterone is allowed to react with 